\title{
Roles of inflammation factors in melanogenesis (Review)
}

\author{
CHUHAN FU* ${ }^{*}$,JING CHEN*, JIANYUN LU, LU YI, XIAOLIANG TONG, \\ LIYANG KANG, SHIYAO PEI, YUJIE OUYANG, LING JIANG, YUFANG DING, \\ XIAOJIAO ZHAO, SI LI, YAN YANG, JINHUA HUANG and QINGHAI ZENG
}

Department of Dermatology, Third Xiangya Hospital of Central South University, Changsha, Hunan 410013, P.R. China

Received January 29, 2019; Accepted September 24, 2019

DOI: $10.3892 / \mathrm{mmr} .2020 .10950$

\begin{abstract}
The occurrence of hyperpigmentation or hypopigmentation after inflammation is a common condition in dermatology and cosmetology. Since the exact mechanism of its occurrence is not yet known, prevention and treatment are troublesome. Previous studies have confirmed that $\alpha$-melanocyte-stimulating hormone, stem cell factor and other factors can promote melanogenesis-related gene expression through the activation of signaling pathways. Recent studies have revealed that a variety of inflammatory mediators can also participate in the regulation of melanogenesis in melanocytes. In this review, we summarized that interleukin-18, interleukin-33, granulocyte-macrophage colony stimulating factor, interferon- $\gamma$, prostaglandin E2 have the effect of promoting melanogenesis, while interleukin-1, interleukin-4, interleukin-6, interleukin-17 and tumor necrosis factor can inhibit melanogenesis. Further studies have found that these inflammatory factors may activate or inhibit melanogenesis-related signaling pathways (such as protein kinase A and mitogen activated protein kinase) by binding to corresponding receptors, thereby promoting or inhibiting the expression of melanogenesis-related genes and regulating skin pigmentation processes. This suggests that the development of drugs or treatment methods from the perspective of regulating inflammation can provide new ideas and new targets for the treatment of pigmented dermatosis. This review outlines the current understanding of the inflammation factors' roles in melanogenesis.
\end{abstract}

Correspondence to: Dr Jinhua Huang or Dr Qinghai Zeng, Department of Dermatology, Third Xiangya Hospital of Central South University, 138 Tongzipo Road, Changsha, Hunan 410013, P.R. China

E-mail: huangjinhua60@163.com

E-mail: 271594943@qq.com

${ }^{*}$ Contributed equally

Key words: hypopigmentation, hyperpigmentation, inflammatory factor, melanogenesis, pigmented dermatosis

\section{Contents}

1. Introduction

2. Process of melanogenesis

3. Signaling pathways regulating melanogenesis

4. Function and mechanism of inflammatory factors in regulating melanogenesis

5. Post-inflammatory hyperpigmentations and hypopigmentations can be treated by regulating local inflammatory factors

6. Conclusions and outlook

\section{Introduction}

A coordination system has been formed under the interaction of various cells in the skin. For instance, the cutaneous neuron-immune-endocrine system consists of interaction and coordination between keratinocytes, melanocytes and dendritic Langerhans cells in the epidermis and the components of the dermis such as mast cells, macrophages, fibroblasts and nerve cells (1-3). Allergens, pathogens, chemical stimuli, and physical damage can all lead to skin inflammation (4-7), which is a defense response to exogenous or endogenous stimuli (8). Skin inflammation plays a crucial role in the body, such as resisting the invasion of bacteria and other pathogens and promoting the repair of wounds. Recent studies have revealed that inflammatory cytokines are closely related to skin pigmentation $(9,10)$.

Skin hyperpigmentation or hypopigmentation after inflammation is a clinically common symptom. Various acute or chronic inflammatory skin reactions may cause changes in skin pigmentation (11), such as psoriasis, eczema, or laser surgery. Recent studies have confirmed that interleukin (IL)-1, IL-4, IL-6 and other inflammatory mediators can regulate the proliferation and differentiation of human epidermal melanocytes directly or indirectly and participate in the regulation of melanogenesis in melanocytes (11-13). Treatments that modulate these inflammatory mediators may have great clinical utility in the treatment of some dyschromatosis (14). This review will focus on the role of inflammatory factors in melanogenesis and the mechanisms involved.

\section{Process of melanogenesis}

Melanocytes originate from the ectodermal neural crest, migrate to the mesenchyme as the embryo develops, and 
then further migrate to the skin, eye uveal, stria vascularis, vestibular organ, endolymphatic sac and pia mater $(15,16)$. The migration, proliferation, and differentiation of melanoblasts are mainly regulated by regulatory factors secreted by the dorsal neural tube, ectoderm, and keratinocytes such as the fmily of Wingless-type protein (WNT), endothelin 3 (EDN3), and stem cell factor (SCF) (17). Melanogenesis in mature melanocytes occurs in melanosomes. Melanosomes are unique organelles located in the cytoplasm of melanocytes, which contain key enzymes regulating the production of pigments such as tyrosinase (TYR), tyrosinase-related protein-1 (TYRP-1) and tyrosinase-related protein-2 (TYRP-2) (17,18). Activation of the transcription factor microphthalmia-associated transcription factor (MITF) (19-21) results in the upregulation of the expression of key genes such as TYR, TYRP-1 and TYRP-2 $(16,22,23)$, and promotes melanogenesis in melanocytes (17). Mature melanosomes can migrate from the perinuclear region to the dendrites of melanocyte under the regulation of tubulin (kinesin, dynein) (17). In the epidermis, melanocytes are associated with 30 to 40 keratinocytes through dendrites, transferring mature melanosomes into the cytoplasm of keratinocytes $(15,24)$.

\section{Signaling pathways regulating melanogenesis}

Multiple signaling pathways are involved in the regulation of melanogenesis, with the cyclic AMP (cAMP)/protein kinase A (PKA) signaling pathway being one of the most important signaling pathways (Fig. 1). The most well-known receptor on melanocytes that modulates their function is the melanocortin-1 receptor (MC1R). When $\alpha$-melanocyte-stimulating hormone ( $\alpha-\mathrm{MSH})$ binds to MC1-R on the membrane of melanocytes, it activates adenylate cyclase, increases intracellular cAMP, activates PKA-cAMP response element-binding protein (CREB) pathway, and then increases MITF, promoting melanogenesis (25-28). MC1R is also a major regulator of human pigmentation and is also a melanoma susceptibility gene (28). In addition, signaling pathways such as mitogen activated protein kinase (MAPK), inositol trisphosphate/diacylglycerol (IP3/DAG), WNT, and protein kinase C (PKC) have also been revealed to participate in melanogenesis. The $\alpha 1$ adrenergic receptor can activate the IP3/DAG pathway and increase the intracellular levels of PKC- $\beta$ and activate tyrosinase (29). SCF, GM-SCF and hepatocyte growth factor (HGF) can activate signaling pathways mediated by the corresponding receptor c-KIT, GM-CSFR, and HGFR, leading to autophosphorylation and activation of MAP kinase, thereby phosphorylating MITF, upregulating the expression of melanogenesis-related enzymes (30-32). The WNT signaling pathway can activate MITF-M promoter (33-35), thereby resulting in upregulation of MITF expression to further regulate melanogenesis. Catecholamines can promote melanogenesis through the cAMP/PKA pathway, while catecholamines also mediate melanogenesis through the activation of PKC- $\beta$ pathways by $\alpha 1$ and $\beta 2$ adrenergic receptors $(29,36)$.

Skin melanogenesis is affected by the epidermal melanin unit, which is mainly composed of keratinocytes and melanocytes. Many of the paracrine factors secreted by keratinocytes can act on melanocytes to promote or inhibit melanogenesis. For example, IL-18, IL-33, GM-CSF can promote melanogenesis, and TNF, IL-1 and IL-6 can inhibit melanogenesis $(37,38)$. In addition to keratinocytes, other types of cells in the skin, such as fibroblasts, also participate in the regulation of melanocytes by producing paracrine factors (Fig. 2). Melanocytes interact with these surrounding cells by expressing corresponding receptors on the cell surface (27). In addition, studies have revealed that paracrine factors can provide a variety of mechanisms to activate DNA repair mechanisms by activating different receptors and signaling pathways to maintain melanocyte homeostasis and prevent UV mutagenesis (28).

\section{Function and mechanism of inflammatory factors in regulating melanogenesis}

Inflammation is a basic pathological process mainly involving defensive reactions of living tissues with a vascular system in response to the stimulation of various damage factors. The chemical factors involved in mediating inflammatory reactions are called chemical mediators or inflammatory mediators. The inflammatory mediators in the skin are mainly secreted by Th cells, lymphocytes, monocytes-macrophages, dendritic cells, and the like. Th cells are mainly classified as Th1 and Th2 cells (39). Th1 cells play an important role in cellular immune responses, secreting cytokines such as interferon- $\gamma(\mathrm{IFN}-\gamma)$, tumor necrosis factor (TNF), IL-2, IL-3, GM-CSF; Th2 cells play a key part in humoral immune responses, secreting IL-4, IL-5, IL-10, IL-13, IL-3, GM-CSF as well as other cytokines $(40,41)$. In a normal body, Th1 cytokines and Th2 cytokines are in equilibrium. When the body suffers from a certain disease, the balance between Th1 and Th2 is impaired, and there is a drift toward Th1 or Th2 (39). T helper cell 17 (Th17) is a newly discovered T cell subset that secretes IL-17, IL-6, IL-21 and IL-22 and participates in the occurrence of innate immunity and certain inflammations by secreting IL-17, IL-6 and TNF- $\alpha$. Studies have revealed that keratinocytes can secrete IL-18, TNF, IL-1, GM-CSF, INF- $\gamma$, and IL-3, fibroblasts can secrete IL-33, TNF, IL-6, and IL-8, and melanocytes can secrete INF- $\beta$, IL-1, IL-8, IL-10 and TNF- $\alpha(37,38,42)$. The main inflammatory mediators that are secreted by various types of cells in the skin are presented in Table I. Recent studies have revealed that local inflammatory factors of the skin may be involved in the regulation of skin pigmentation (Fig. 3). The function and mechanisms of these inflammatory factors in regulating melanogenesis are presented in Table II.

IL-18 is produced by inflammatory stimuli in Langerhans cells (LC), dendritic cells (DC), Kupffer cells, activated monocytes/macrophages, and keratinocytes in the epidermis (43-45). IL-18 has been revealed to increase the cascade expression of MITF and downstream enzymes by activating the p38/MAPK and PKA pathways, and thus promote melanogenesis and upregulate TYRP-1 and TYRP-2 expression $(43,46)$. These results suggest that IL-18 may participate in the regulation of pigmentation by regulating melanocytes.

IL-33 can induce mast cells to produce pro-inflammatory cytokines and chemokines (47-51), thereby activating macrophages (52-54), CD4 ${ }^{+} \mathrm{T}$ cells, basophils, dendritic cells and neutrophils $(47,55-58)$, and promoting skin inflammation. It has been revealed that IL-33 mRNA is expressed in multiple organs in humans (including the skin), and in particular, relatively abundant IL-33 mRNA is found in keratinocytes 


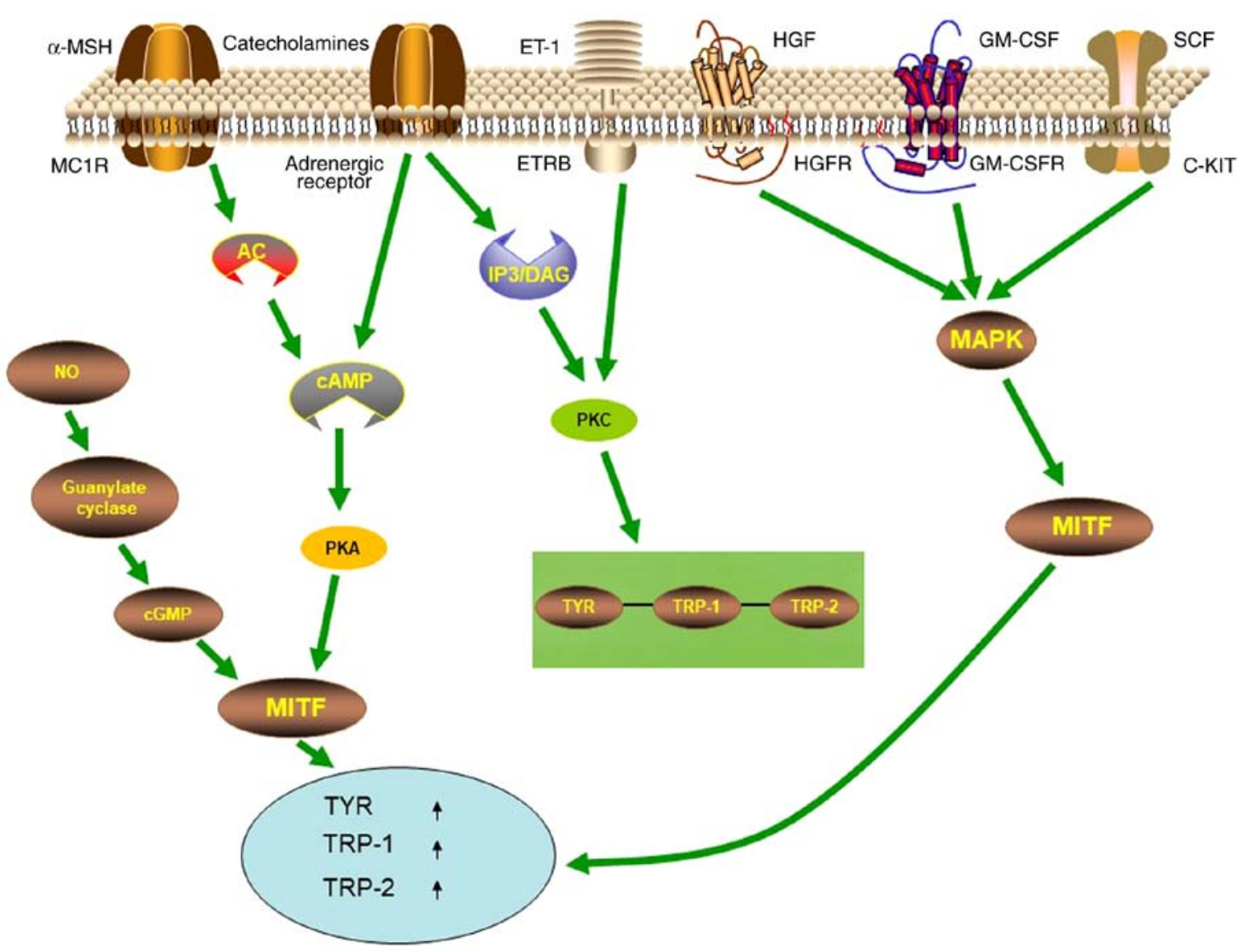

Figure 1. Different signaling pathways regulating melanogenesis. Upon binding to MCIR and adrenergic receptor respectively, $\alpha$-MSH and catecholamines activate the PKA pathway by increasing cAMP. Then PKA promotes MITF expression, which controls the expression of melanogenesis-related genes TYR, TRP-1 and TRP-2. Upon binding to ETR and adrenergic receptor respectively, ET-1 and catecholamines activate the PKC pathway to promote the expression of TYR, TRP-1 and TRP-2. Upon binding to c-MET, GM-CSFR, and c-KIT and respectively, HGF, GM-CSF, and SCF activate the MAPK pathway to promote the expression of MITF, which in turn increases the expression of TYR, TRP-1 and TRP-2. In addition, NO in the cytoplasm regulates MITF-driven expression of TYR, TRP-1 and TRP-2 through the guanylate cyclase-cGMP pathway. $\alpha$-MSH, $\alpha$-melanocyte-stimulating hormone; MC1R, melanocortin-1 receptor; ET-1, endothelin-1; ETR, ET-receptor; HGF, hepatocyte growth factor; GM-CSF, granulocyte-macrophage colony-stimulating factor; GM-CSFR, granulocyte macrophage colony-stimulating factor receptor; SCF, stem cell factor; AC, adenylate cyclase; cAMP, 3'5'-cyclic adenosine monophosphate; PKA, protein kinase A; c-GMP, cyclic guanosine monophosphate; IP3/DAG, inositol trisphosphate/diacylglycerol; PKC, protein kinase C; MAPK, mitogen activated protein kinase; TYR, tyrosinase; TRP-1, tyrosinase-related protein-1; TRP-2, tyrosinase-related protein-2.

and fibroblasts $(59,60)$. Research has revealed that IL-33 can improve melanin biosynthesis in NHEM and promote the expression of MITF and its downstream-regulated tyrosine, TYRP-1, and TYRP-2 through the activation of MAPK and PKA pathways (14), thereby promoting melanogenesis.

In addition, granulocyte-macrophage colony-stimulating factor (GM-CSF) which is produced by mononuclear macrophages, keratinocytes and Th cells, has been revealed to promote melanocyte proliferation and melanin synthesis (17). $\mathrm{Wu}$ et al revealed that increased serum levels of GM-CSF may be used as the serum biomarkers to predict the prognosis of TCAM (transplantation of cultured autologous melanocytes) when vitiligo patients are treated (61).

Prostaglandin E2 (PGE2) and PGF2 $\alpha$ which are produced by fibroblasts and keratinocytes have been revealed to stimulate dendritic cell formation and activate tyrosinase in melanocytes through their dependence on the cAMP signaling pathway and phospholipase C (PLC) $(62,63)$. Ma et al revealed that PGE2 is important in melanosome transfer by promoting filopodia delivery (including miniaturization of melanosome, filopodia formation, and broadening diameter of filopodia) and the number of shedding spheroid granules in primary melanocytes (MCs), but has no effects on morphological observation of KCs (64).

As one of the most important endogenous mediators of immunity and inflammation, IFN- $\gamma$ is also a common secretory cytokine in the skin (46). As a pro-inflammatory cytokine, IFN- $\gamma$ is mainly secreted by Th1 lymphocytes, $\mathrm{CD} 8^{+}$cytotoxic $\mathrm{T}$ lymphocytes and NK cells (65). Other cells, including antigen-presenting cells, B cells and NKT cells, can also secrete IFN- $\gamma$ (66-68). Recent studies have demonstrated that the local accumulation of IFN- $\gamma$ through melanocyte-specific $\mathrm{CD}^{+} \mathrm{T}$ cells plays an important role in skin discoloration spots in various mouse models of vitiligo $(69,70)$. Yang et al reported that increased IFN- $\gamma$ is essential for the pathogenesis of vitiligo by inducing apoptosis of melanocytes (71). Natarajan et al revealed that IFN- $\gamma$ signaling blocks maturation of melanosomes by regulating pigmentation genes (72). Moreover, IFN- $\gamma$ has been revealed to regulate melanogenesis by upregulating STAT1 phosphorylation, and its inhibiting effect can be restrained by JAK1 inhibitors. Studies have also revealed that IFN- $\gamma$ inhibits IL-18-induced melanogenesis (46). 


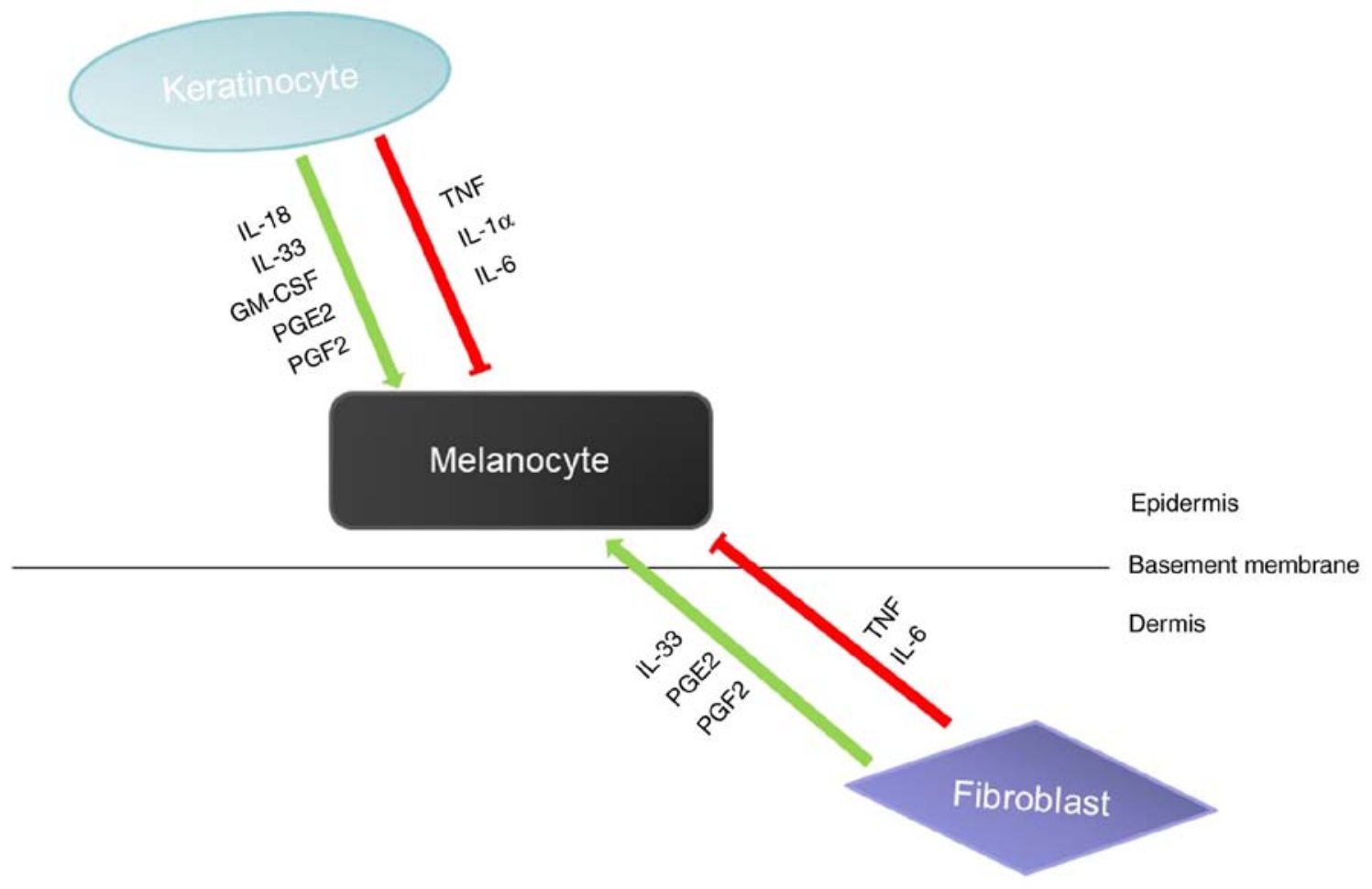

Figure 2. Keratinocyte-derived factors and fibroblast-derived factors that affect melanogenesis in melanocytes through a paracrine effect. Various factors are identified to stimulate (green arrows) or inhibit (red arrows) melanogenesis in melanocytes. Keratinocytes secret factors such as IL-18, IL-33, GM-CSF, PGE2 and PGF2 to stimulate melanocyte melanogenesis as well as TNF, IL-1 $\alpha$ and IL-6 to inhibit melanocyte melanogenesis. Fibroblast-derived factors such as IL-33, PGE2 and PGF2 stimulate melanocyte melanogenesis while TNF and IL-6 inhibit melanocyte melanogenesis. IL-18, interleukin-18; IL-33, interleukin-33; GM-CSF, granulocyte-macrophage colony stimulating factor; PGE2, prostaglandin E2; PGF2, prostaglandin F2; TNF, tumor necrosis factor; IL-1 $\alpha$, interleukin-1 $\alpha$; IL-6, interleukin-6.

TNF is a homotrimeric cytokine, secreted mainly by monocytes and macrophages, and also by keratinocytes, dendritic cells, Th1, Th17 and Th22. It functions by binding to two different receptors: TNFR1/p55 and TNFR2/p75 (9). TNF not only induces inflammation through the activation of vascular endothelial cells and immune cells, but also acts as an important regulator of lymphoid tissue development by controlling apoptosis (9). Elevated levels of TNF have been revealed at sites of inflammation in several autoimmune diseases, and inflammatory symptoms have generally decreased after neutralization of TNF. For instance, higher expression levels of TNF, TNFR1 and TNFR2 are observed in psoriasis (73). Studies have revealed that after treatment of melanocytes with both IL-17 and TNF for 24-48 h, the levels of c-KIT, MC1-R, MITF, and TYRP-2 were on the decrease, and the levels of tyrosinase and melanin were significantly reduced (10). It has been revealed that, through the combination with IL-17, TNF can inhibit melanogenesis by PKA and MAPK signaling pathways $(9,10)$. Blocking TNF can lead to rapid restoration of pigmentation gene expression in psoriatic lesions. This suggests that anti-TNF has the potential of treating pigmented dermatosis (10).

IL-1 is an important pro-inflammatory cytokine in innate immunity that stimulates the differentiation and function of immune surveillance cells and contributes to increased tumor invasiveness, metastasis, and angiogenesis under chronic inflammatory conditions (74). IL-1 $\alpha$ is an inflammatory mediator mainly produced by Langerhans cells, and is also secreted by melanocytes and keratinocytes. Its signal transduction is initiated by binding to IL-1 receptor type I (IL-1R $\alpha$ chain) (75), which can inhibit tyrosinase activity and melanogenesis (12,74). Of its many activities, IL-1 $\alpha$ also stimulates human fibroblasts to produce keratinocyte growth factor (KGF) (76). Keratinocytes store a large amount of active IL- $1 \alpha$, express IL-1 receptors (77) and produce more IL-1 $\alpha$ upon ultraviolet B (UVB) exposure (78). KGF is thought to induce TYR expression in primary melanocytes (79). The combination of KGF and IL- $1 \alpha$ increases melanin deposition and they may be involved in the initial stage of human Solar lentigines lesion formation (79). Although they share only $24 \%$ identity in protein sequence, IL-1 $\beta$ and IL- $1 \alpha$ fold in a highly similar manner and recognize the same receptor, the type I IL-1 receptor (IL-1RI) (80). After treatment of a panel of melanoma cell lines with IL-1 $\beta$, it was observed that most of the MITF-M was inhibited and was NF- $\mathrm{KB}$ - and JNK-dependent. The inactivation of these two pathways could eliminate the inhibitory effects of IL-1 $\beta$ on melanin, which indicated that IL- $1 \beta$ could downregulate MITF-M through NF-kB and JNK pathways, thereby inhibiting melanogenesis (74).

IL- 4 is a cytokine mainly secreted by Th 2 cells and can also be produced by CD8-positive cytotoxic T cells, basophils, eosinophils, and mast cells in chronic inflammation $(81,82)$. IL-4 plays a key role in the generation of the major mediator $\operatorname{IgE}$ in hypersensitivity as well as in the induction of inflammation, contributing to the autoimmunity of the body (83). IL-4 is involved in the maintenance of Th2 lymphocytes and acts as an autocrine growth factor of differentiated Th2 cells (84). It is hypothesized that vitiligo 
Table I. Inflammatory mediators secreted by various types of cells in the skin.

\section{Cell type}

Inflammatory factors

Mononuclear macrophages

Neutrophils

Th1 cells

Th2 cells

Th17 cells

Mast cells

Dendritic cells

Keratinocytes

Melanocytes

Fibroblasts
INF- $\gamma$, TNF, IL-1, GM-CSF, IL-6, IL-8, IL-12, IL-18, IL-10

IL-1 $\beta$, TNF, IL-6, IL-8, IL-15, IFN- $\gamma$

IFN- $\gamma$, TNF, IL-2, IL-3, GM-CSF

IL-4, IL-5, IL-6, IL-10, IL-13, IL-3, GM-CSF

IL-17, IL-6, IL-21, IL-22, TNF- $\alpha$

TNF, IL-1, IL-4, IL-6, IL-8, IL-10, IL-13, IFN- $\gamma$

IL-2, IL-4, IL-5, IL-12, INF- $\gamma$

IL-18, TNF, IL-1, GM-CSF, INF- $\gamma$, IL-33

INF- $\beta$, IL- 1, IL- 8, IL-10, TNF- $\alpha$

IL-33, TNF, IL-6, IL-8

Th1, Thelper 1; IFN- $\gamma$, interferon- $\gamma$; TNF, tumor necrosis factor; IL, interleukin; GM-CSF, granulocyte-macrophage colony stimulating factor.

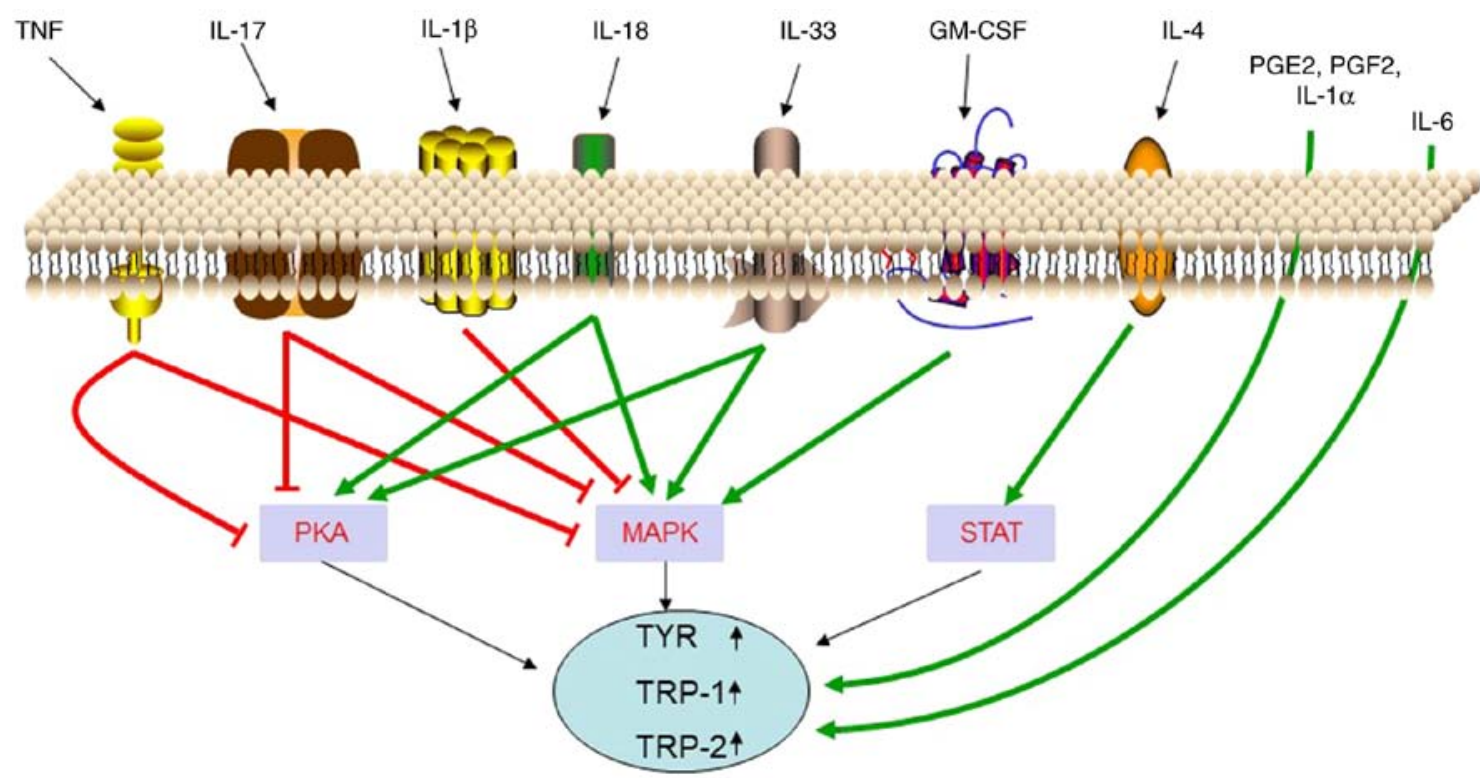

Figure 3. Cytokines that inhibit or stimulate melanogenesis. Cytokines such as TNF, IL-17 and IL-1 $\beta$ inhibit melanogenesis by suppressing the PKA or MAPK pathway. While cytokines such as IL-18, IL-33 and GM-CSF stimulate melanogenesis by stimulating the PKA or MAPK pathway. IL-4 stimulates melanogenesis by stimulating the STAT pathway. PGE2, PGF2, IL-1 $\alpha$ and IL-6 stimulate melanogenesis through unidentified signaling pathways. TNF, tumor necrosis factor; IL-17, interleukin-17; IL-1 $\beta$, interleukin-1 $\beta$; IL-18, interleukin-18; IL-33, interleukin-33; GM-CSF, granulocyte-macrophage colony stimulating factor; IL-4, interleukin-4; PGE2, prostaglandin E2; PGF2, prostaglandin F2; IL-1 $\alpha$, interleukin-1 $\alpha$; IL-6, interleukin-6; PKA, protein kinase A; MAPK, mitogen activated protein kinase; STAT, signal transducer and activator of transcription; TYR, tyrosinase; TRP-1, tyrosinase-related protein-1; TRP-2, tyrosinase-related protein-2.

development is directly affected by the imbalance of the Th1/Th2 response (85). Nouri-Koupaee et al revealed the Th1 and Th2 response profiles in vitiligo by assessing IFN- $\gamma$ and IL-4. This study revealed significant increases in IFN- $\gamma$ and marked decreases of IL-4 in patients when compared to controls (86). It has also been revealed that IL-4 downregulates the expression of MITF, TYRP-1, and TYRP-2 through the JAK2/STAT6 signaling pathway and thus inhibits melanogenesis (13).

IL-6 is secreted by keratinocytes, epidermal cells, fibroblasts and dermal endothelial cells and is involved in the regulation of various biological responses including immune response, inflammation, hematopoiesis, and tumorigenesis by regulating cell growth, survival, and differentiation (87). Research has revealed that IL-6 decreases tyrosinase activity and melanogenesis (12).

IL-17 is a pro-inflammatory cytokine produced mainly by Th17 cells, and also by other immune cells, including neutrophils, natural killer cells, mast cells, $\alpha \beta$ and $\gamma \delta \mathrm{T}$ cells (88). The most well-known function of IL-17 is to prevent bacterial and fungal infections (88). IL-17 has a variety of inflammatory effects, resulting in the release of large amounts of cytokines from a variety of cells, such as epithelial cells, endothelial cells, and fibroblasts (89). Studies have revealed that IL-17 can bind to TNF to inhibit the signaling pathway for melanogenesis, thereby inhibiting melanogenesis (10). The function 
Table II. Function and mechanisms of inflammatory factors in the regulation of melanogenesis.

\begin{tabular}{|c|c|c|c|c|}
\hline Factor & Experimental cells & $\begin{array}{c}\text { Effect on } \\
\text { melanogenesis }\end{array}$ & Mechanisms & (Refs.) \\
\hline IL-18 & Keratinocyte & Promotion & $\begin{array}{l}\text { Increasing tyrosinase activity and upregulating } \\
\text { TYRP-1 and TYRP-2 expression }\end{array}$ & (43) \\
\hline IL-33 & Melanocytes & Promotion & $\begin{array}{l}\text { Promoting MITF, TYR, TYRP-1, TYRP-2 } \\
\text { expression by activating the p38/MAPK } \\
\text { and PKA pathways }\end{array}$ & (14) \\
\hline GM-CSF & Melanocytes & Promotion & $\begin{array}{l}\text { Promoting melanocyte proliferation and melanin } \\
\text { synthesis }\end{array}$ & $(17)$ \\
\hline PGE2 and PGF2 $\alpha$ & Keratinocytes & Promotion & $\begin{array}{l}\text { Stimulating melanocyte dendrite formation } \\
\text { through a cAMP-dependent pathway }\end{array}$ & $(62)$ \\
\hline IFN- $\gamma$ & $\mathrm{B} 16 \mathrm{~F} 10$ & Inhibition & $\begin{array}{l}\text { Blocking maturation of melanosome and } \\
\text { upregulating STAT1 phosphorylation }\end{array}$ & $(46,72)$ \\
\hline TNF & $\begin{array}{l}\text { Melanocytes, } \\
\text { primary pooled } \\
\text { human keratinocytes }\end{array}$ & Inhibition & $\begin{array}{l}\text { Inhibiting melanin formation through PKA and } \\
\text { MAPK signaling pathways in combination with } \\
\text { IL-17 }\end{array}$ & $(10)$ \\
\hline IL-1 $\alpha$ & $\begin{array}{l}\text { Primary melanocytes, } \\
\text { swine skin }\end{array}$ & Promotion & Combination of KGF increases melanin deposition & $(79)$ \\
\hline IL-1 $\beta$ & $\begin{array}{l}\text { Melanoma cell lines } \\
\text { (LB2259-MEL and } \\
\text { CP50-MEL) }\end{array}$ & Inhibition & $\begin{array}{l}\text { Downregulating MITF-M expression through } \\
\text { NF- } \kappa \text { B and JNK pathways }\end{array}$ & (74) \\
\hline IL-4 & Melanocytes & Inhibition & $\begin{array}{l}\text { Downregulating the expression of MITF, TYRP-1, } \\
\text { TYRP-2 through the JAK2-STAT6 signaling } \\
\text { pathway }\end{array}$ & (13) \\
\hline IL-6 & Melanocytes & Inhibition & Decreasing tyrosinase activity & (12) \\
\hline IL-17 & $\begin{array}{l}\text { Melanocytes, } \\
\text { primary pooled } \\
\text { human keratinocytes }\end{array}$ & Inhibition & $\begin{array}{l}\text { Inhibiting melanin formation through PKA and } \\
\text { MAPK signaling pathways in combination with } \\
\text { TNF }\end{array}$ & $(10)$ \\
\hline
\end{tabular}

TYRP-1, tyrosinase-related protein-1; TYRP-2, tyrosinase-related protein-2; MITF, microphthalmia-associated transcription factor; TYR, tyrosinase; PKA, protein kinase A; MAPK, mitogen activated protein kinase; JNK, c-Jun N-terminal kinase; JAK-STAT, Janus kinase-signal transducer and activator of transcription.

and mechanisms of these inflammatory factors in regulating melanogenesis are presented in Table II.

It should be noted that the IFN- $\gamma$-related data were acquired from a murine melanoma model (B16F10) and IL-1 $\alpha$-related data were based on observations from porcine skin. Therefore, whether their effects on melanogenesis in human melanocytes are the same still requires confirmation by subsequent experiments.

\section{Post-inflammatory hyperpigmentations and hypo- pigmentations can be treated by regulating local inflammatory factors}

In clinical practice, various treatments can be effective for post-inflammatory hyperpigmentations and hypopigmentations by influencing inflammatory factors. For example, chloasma is a postinflammatory hyperpigmented disease caused by many factors such as heredity, ultraviolet radiation, pregnancy, hormone therapy, cosmetics, and phototoxic drugs (90). Kojic acid, hydroquinone, and tranexamic acid are commonly used to treat melasma (91). It is well-known that their inhibitory effect on tyrosine activity or melanocyte-specific cytotoxicity is the decolorization mechanism $(92,93)$. In recent years, it has been revealed that kojic acid also inhibits the melanogenesis of melanocytes by promoting the expression of IL-6 in keratinocytes. Resveratrol was revealed to play an important role in ameliorating inflammation, including skin inflammation and reducing inflammatory injury in $\mathrm{HaCaT}$ cells (94). Studies have also reported that resveratrol inhibits melanin synthesis to treat hyperpigmented diseases (95). Therefore, resveratrol may also affect melanogenesis by regulating inflammatory factors.

Although the causes of vitiligo are not completely clear, inflammation has been revealed to play a role in its pathogenesis (96). Certain studies revealed that higher expression of pro-inflammatory cytokines had an inhibitory effect on pigmentation in vitiligo lesions $(97,98)$. For example, Kim et al (99) revealed that increased expression of TNF- $\alpha$ in keratinocytes of the lesion area in vitiligo patients inhibited the secretion of melanocyte growth factor from KCs. Barygina et al suggested that low-dose IL-4, $\beta$-endorphin, bFGF and IL-10 may be considered as new therapeutic tools for vitiligo treatment (100). 
Studies have revealed that $308 \mathrm{~nm}$ excimer laser can significantly reduce the level of TNF- $\alpha$ in lesions (101), thereby promoting $\mathrm{MC}$ function. Various studies reported that the expression of IL-4, TNF- $\alpha$ and other inflammatory cytokines was downregulated after topical application of tacrolimus in lesions of vitiligo $(102,103)$. Methotrexate (MTX) is used in the treatment of autoimmune diseases to decrease T cells that produce TNF- $\alpha$, which is a key step in the development of vitiligo (104). A study by Alghamdi and Khurrum revealed that oral MTX was a safe and effective therapeutic approach for vitiligo, however, due to the fact that this was a small uncontrolled pilot study, further research needs to be carried out (105). Afamelanotide is a potent and longer-lasting synthetic analogue of naturally occurring $\alpha$-MSH, which is decreased in vitiligo. Grimes et al (106) found that NB-UVB combined with afamelanotide is safe and effective and that afamelanotide represents a potentially effective treatment for vitiligo, however this still requires further studies. The aforementioned findings indicated that the external use of medications, light therapy and other treatments may serve to treat inflammation related-hyperpigmentations or hypopigmentations by regulating the expression of inflammatory factors associated with melanin production.

\section{Conclusion and outlook}

Studies have revealed that a variety of inflammatory factors can promote or inhibit the melanogenesis of melanocytes through different mechanisms, suggesting that the development of medicine or therapies from the perspective of inflammation regulation can provide new ideas and new targets for the treatment of pigmented dermatosis. It is widely considered that the regulatory network of inflammation is very complex, since all types of inflammatory cells are involved in the activation and release of inflammatory mediators. The imbalance of inflammatory factors related to T-cell subsets plays an important role in the development of various skin diseases, however, the relationship between imbalance or changes of T-cell subsets and melanogenesis has yet to be confirmed by further experiments.

\section{Acknowledgements}

Not applicable.

\section{Funding}

The present study was supported by the Fundamental Research Funds for the Central Universities of Central South University (no. 2017zzts890), the National Natural Science Foundation of China (no. 81703101) and the Natural Science Foundation of Hunan Province (nos. 2018JJ3788 and 2018JJ3793).

\section{Availability of data and materials}

The datasets used during the present study are available from the corresponding author upon reasonable request.

\section{Authors' contributions}

$\mathrm{CF}$ and JC designed and wrote the paper. JH and QZ designed and supervised the study. JL, LY, XT, LK, SP, YO, LJ, YD,
XZ, SL and YY analyzed and interpreted the data. All authors have read and approved the final manuscript and agreed to be accountable for all aspects of the work in ensuring that questions related to the accuracy or integrity of any part of the work are appropriately investigated and resolved.

\section{Ethics approval and consent to participate}

Not applicable.

\section{Patient consent for publication}

Not applicable.

\section{Competing interests}

The authors declare that they have no interests.

\section{References}

1. Gröne A: Keratinocytes and cytokines. Vet Immunol Immunopathol 88: 1-12, 2002.

2. Skobowiat C, Dowdy JC, Sayre RM, Tuckey RC and Slominski A: Cutaneous hypothalamic-pituitary-adrenal axis homolog: Regulation by ultraviolet radiation. Am J Physiol Endocrinol Metab 301: E484-E493, 2011.

3. Weiss E, Mamelak AJ, La Morgia S, Wang B, Feliciani C, Tulli A and Sauder DN: The role of interleukin 10 in the pathogenesis and potential treatment of skin diseases. J Am Acad Dermatol 50: 657-678, 2004.

4. Martin SF: Contact dermatitis: From pathomechanisms to immunotoxicology. Exp Dermatol 21: 382-389, 2012.

5. Miller LS and Cho JS: Immunity against Staphylococcus aureus cutaneous infections. Nat Rev Immunol 11: 505-518, 2011.

6. Behrends U, Peter RU, Hintermeier-Knabe R, Eissner G, Holler E, Bornkamm GW, Caughman SW and Degitz K: Ionizing radiation induces human intercellular adhesion molecule-1 in vitro. J Invest Dermatol 103: 726-730, 1994.

7. Fuchs $\mathbf{J}$ and Kern H: Modulation of UV-light-induced skin inflammation by D-alpha-tocopherol and L-ascorbic acid: A clinical study using solar simulated radiation. Free Radic Biol Med 25: 1006-1012, 1998.

8. Basler K and Brandner JM: Tight junctions in skin inflammation. Pflugers Arch 469: 3-14, 2017.

9. Grine L, Dejager L, Libert C and Vandenbroucke RE: An inflammatory triangle in psoriasis: TNF, type I IFNs and IL-17. Cytokine Growth Factor Rev 26: 25-33, 2015.

10. Wang CQF, Akalu YT, Suarez-Farinas M, Gonzalez J, Mitsui H, Lowes MA, Orlow SJ, Manga P and Krueger JG: IL-17 and TNF synergistically modulate cytokine expression while suppressing melanogenesis: Potential relevance to psoriasis. J Invest Dermatol 133: 2741-2752, 2013.

11. Slominski A, Tobin DJ, Shibahara S and Wortsman J: Melanin pigmentation in mammalian skin and its hormonal regulation. Physiol Rev 84: 1155-1228, 2004.

12. Swope VB, Abdel-Malek Z, Kassem LM and Nordlund JJ: Interleukins 1 alpha and 6 and tumor necrosis factor-alpha are paracrine inhibitors of human melanocyte proliferation and melanogenesis. J Invest Dermatol 96: 180-185, 1991.

13. Choi H, Choi H, Han J, Jin SH, Park JY, Shin DW, Lee TR, Kim K, Lee AY and Noh M: IL-4 inhibits the melanogenesis of normal human melanocytes through the JAK2-STAT6 signaling pathway. J Invest Dermatol 133: 528-536, 2013.

14. Zhou J, Song J, Ping F and Shang J: Enhancement of the p38 MAPK and PKA signaling pathways is associated with the pro-melanogenic activity of Interleukin 33 in primary melanocytes. J Dermatol Sci 73: 110-116, 2014.

15. Tsatmali M, Ancans J and Thody AJ: Melanocyte function and its control by melanocortin peptides. J Histochem Cytochem 50: 125-133, 2002.

16. Costin GE and Hearing VJ: Human skin pigmentation: Melanocytes modulate skin color in response to stress. FASEB J 21: 976-994, 2007. 
17. Videira IF, Moura DF and Magina S: Mechanisms regulating melanogenesis. An Bras Dermatol 88: 76-83, 2013.

18. Yamaguchi $Y$, Brenner $M$ and Hearing VJ: The regulation of skin pigmentation. J Biol Chem 282: 27557-27561, 2007.

19. Seong ZK, Lee SY, Poudel A, Oh SR and Lee HK: Constituents of cryptotaenia japonica inhibit melanogenesis via CREB- and MAPK-associated signaling pathways in murine B16 melanoma cells. Molecules 21: pii: E1296, 2016.

20. Campos PM, Prudente AS, Horinouchi CD, Cechinel-Filho V, Fávero GM, Cabrini DA and Otuki MF: Inhibitory effect of GB-2a (I3-naringenin-II8-eriodictyol) on melanogenesis. J Ethnopharmacol 174: 224-229, 2015.

21. Tsao YT, Huang YF, Kuo CY, Lin YC, Chiang WC, Wang WK, Hsu CW and Lee CH: Hinokitiol inhibits melanogenesis via AKT/mTOR signaling in B16F10 mouse melanoma cells. Int J Mol Sci 17: 248, 2016.

22. Hirobe T: Role of keratinocyte-derived factors involved in regulating the proliferation and differentiation of mammalian epidermal melanocytes. Pigment Cell Res 18: 2-12, 2005.

23. Schallreuter KU, Kothari S, Chavan B and Spencer JD: Regulation of melanogenesis-controversies and new concepts. Exp Dermatol 17: 395-404, 2008.

24. Lin JY and Fisher DE: Melanocyte biology and skin pigmentation. Nature 445: 843-850, 2007.

25. Park HY, Kosmadaki M, Yaar M and Gilchrest BA: Cellular mechanisms regulating human melanogenesis. Cell Mol Life Sci 66: 1493-1506, 2009.

26. Schiaffino MV: Signaling pathways in melanosome biogenesis and pathology. Int J Biochem Cell Biol 42: 1094-1104, 2010.

27. Yuan XH and Jin ZH: Paracrine regulation of melanogenesis. $\mathrm{Br}$ J Dermatol 178: 632-639, 2018

28. Swope VB and Abdel-Malek ZA: MC1R: Front and center in the bright side of dark eumelanin and DNA repair. Int J Mol Sci 19: pii: E2667, 2018

29. Grando SA, Pittelkow MR and Schallreuter KU: Adrenergic and cholinergic control in the biology of epidermis: Physiological and clinical significance. J Invest Dermatol 126: 1948-1965, 2006.

30. Bonaventure J, Domingues MJ and Larue L: Cellular and molecular mechanisms controlling the migration of melanocytes and melanoma cells. Pigment Cell Melanoma Res 26: 316-325, 2013

31. Besmer P, Murphy JE, George PC, Qiu FH, Bergold PJ, Lederman L, Snyder HW Jr, Brodeur D, Zuckerman EE and Hardy WD: A new acute transforming feline retrovirus and relationship of its oncogene $\mathrm{v}$-kit with the protein kinase gene family. Nature 320: 415-421, 1986

32. Yarden Y, Kuang WJ, Yang-Feng T, Coussens L, Munemitsu S, Dull TJ, Chen E, Schlessinger J, Francke U and Ullrich A: Human proto-oncogene c-kit: A new cell surface receptor tyrosine kinase for an unidentified ligand. EMBO J 6: 3341-3351, 1987.

33. Dorsky RI, Raible DW and Moon RT: Direct regulation of nacre, a zebrafish MITF homolog required for pigment cell formation, by the Wnt pathway. Genes Dev 14: 158-162, 2000.

34. Flaherty KT, Hodi FS and Fisher DE: From genes to drugs: Targeted strategies for melanoma. Nat Rev Cancer 12: 349-361, 2012.

35. Widlund HR,Horstmann MA,PriceER,Cui J,Lessnick SL, Wu M, He X and Fisher DE: Beta-catenin-induced melanoma growth requires the downstream target Microphthalmia-associated transcription factor. J Cell Biol 158: 1079-1087, 2002.

36. Jung E, Lee J, Huh S, Lee J, Kim YS, Kim G and Park D: Phloridzin-induced melanogenesis is mediated by the cAMP signaling pathway. Food Chem Toxicol 47: 2436-2440, 2009.

37. Satomi H, Wang B, Fujisawa H and Otsuka F: Interferon-beta from melanoma cells suppresses the proliferations of melanoma cells in an autocrine manner. Cytokine 18: 108-115, 2002

38. Mattei S, Colombo MP, Melani C, Silvani A, Parmiani G and Herlyn M: Expression of cytokine/growth factors and their receptors in human melanoma and melanocytes. Int J Cancer 56 853-857, 1994

39. Mosmann TR and Sad S: The expanding universe of T-cell subsets: Th1, Th2 and more. Immunol Today 17: 138-146, 1996.

40. O'Garra A: Cytokines induce the development of functionally heterogeneous T helper cell subsets. Immunity 8: 275-283, 1998.

41. Reiner SL and Seder RA: Dealing from the evolutionary pawnshop: How lymphocytes make decisions. Immunity 11: 1-10, 1999.

42. Bennicelli JL and Guerry D VI: Production of multiple cytokines by cultured human melanomas. Exp Dermatol 2: 186-190, 1993.
43. Zhou J, Shang J, Song J and Ping F: Interleukin-18 augments growth ability of primary human melanocytes by PTEN inactivation through the $\mathrm{AKT} / \mathrm{NF}-\kappa \mathrm{B}$ pathway. Int J Biochem Cell Biol 45: 308-316, 2013.

44. Yun W and Li C: JNK pathway is required for TNCB-induced IL-18 expression in murine keratinocytes. Toxicol In Vitro 24: 1064-1069, 2010.

45. Wittmann M, Macdonald A and Renne J: IL-18 and skin inflammation. Autoimmun Rev 9: 45-48, 2009.

46. Zhou J, Ling J, Wang Y, Shang J and Ping F: Cross-talk between interferon-gamma and interleukin-18 in melanogenesis. J Photochem Photobiol B 163: 133-143, 2016.

47. Ali S, Huber M, Kollewe C, Bischoff SC, Falk W and Martin MU: IL-1 receptor accessory protein is essential for IL-33-induced activation of T lymphocytes and mast cells. Proc Natl Acad Sci USA 104: 18660-18665, 2007.

48. Allakhverdi Z, Smith DE, Comeau MR and Delespesse G: Cutting edge: The ST2 ligand IL-33 potently activates and drives maturation of human mast cells. J Immunol 179: 2051-2054, 2007.

49. Moulin D, Donze O, Talabot-Ayer D, Mezin F, Palmer G and Gabay C: Interleukin (IL)-33 induces the release of pro-inflammatory mediators by mast cells. Cytokine 40: 216-225, 2007.

50. Theoharides TC, Zhang B, Kempuraj D, Tagen M, Vasiadi M, Angelidou A, Alysandratos KD, Kalogeromitros D, Asadi S, Stavrianeas N, et al: IL-33 augments substance P-induced VEGF secretion from human mast cells and is increased in psoriatic skin. Proc Natl Acad Sci USA 107: 4448-4453, 2010.

51. Pushparaj PN, Tay HK, H'ng SC, Pitman N, Xu D, McKenzie A, Liew FY and Melendez AJ: The cytokine interleukin-33 mediates anaphylactic shock. Proc Natl Acad Sci USA 106: 9773-9778, 2009.

52. Kurowska-Stolarska M, Stolarski B, Kewin P, Murphy G, Corrigan CJ, Ying S, Pitman N, Mirchandani A, Rana B, van Rooijen $\mathrm{N}$, et al: IL-33 amplifies the polarization of alternatively activated macrophages that contribute to airway inflammation. J Immunol 183: 6469-6477, 2009.

53. Ohno T, Oboki K, Kajiwara N, Morii E, Aozasa K, Flavell RA, Okumura K, Saito H and Nakae S: Caspase-1, caspase-8, and calpain are dispensable for IL-33 release by macrophages. J Immunol 183: 7890-7897, 2009.

54. Schmieder A, Multhoff G and Radons J: Interleukin-33 acts as a pro-inflammatory cytokine and modulates its receptor gene expression in highly metastatic human pancreatic carcinoma cells. Cytokine 60: 514-521, 2012.

55. Hueber AJ, Alves-Filho JC, Asquith DL, Michels C, Millar NL, Reilly JH, Graham GJ, Liew FY, Miller AM and McInnes IB: IL-33 induces skin inflammation with mast cell and neutrophil activation. Eur J Immunol 41: 2229-2237, 2011.

56. Schmitz J, Owyang A, Oldham E, Song Y, Murphy E, McClanahan TK, Zurawski G, Moshrefi M, Qin J, Li X, et al: IL-33, an interleukin-1-like cytokine that signals via the IL-1 receptor-related protein ST2 and induces T helper type 2-associated cytokines. Immunity 23: 479-490, 2005.

57. Suzukawa M, Iikura M, Koketsu R, Nagase H, Tamura C, Komiya A, Nakae S, Matsushima K, Ohta K, Yamamoto K and Yamaguchi M: An IL-1 cytokine member, IL-33, induces human basophil activation via its ST2 receptor. J Immunol 181: 5981-5989, 2008.

58. Rank MA, Kobayashi T, Kozaki H, Bartemes KR, Squillace DL and Kita H: IL-33-activated dendritic cells induce an atypical TH2-type response. J Allergy Clin Immunol 123: 1047-1054, 2009.

59. Arend WP, Palmer G and Gabay C: IL-1, IL-18, and IL-33 families of cytokines. Immunol Rev 223: 20-38, 2008.

60. Byrne SN, Beaugie C, O'Sullivan C, Leighton S and Halliday GM: The immune-modulating cytokine and endogenous Alarmin interleukin-33 is upregulated in skin exposed to inflammatory UVB radiation. Am J Pathol 179: 211-222, 2011.

61. Wu XG, Hong WS and Xu A: GM-CSF: A possible prognostic serum biomarker of vitiligo patients' considered for transplantation treatment with cultured autologous melanocytes: A pilot study. J Eur Acad Dermatol Venereol 30: 1409-1411, 2016.

62. Scott G, Leopardi S, Printup S, Malhi N, Seiberg M and Lapoint R: Proteinase-activated receptor-2 stimulates prostaglandin production in keratinocytes: Analysis of prostaglandin receptors on human melanocytes and effects of PGE2 and PGF2alpha on melanocyte dendricity. J Invest Dermatol 122: 1214-1224, 2004 
63. Scott G, Jacobs S, Leopardi S, Anthony FA, Learn D, Malaviya R and Pentland A: Effects of PGF2alpha on human melanocytes and regulation of the FP receptor by ultraviolet radiation. Exp Cell Res 304: 407-416, 2005.

64. Ma HJ, Ma HY, Yang Y, Li PC, Zi SX, Jia CY and Chen R: a-Melanocyte stimulating hormone (MSH) and prostaglandin E2 (PGE2) drive melanosome transfer by promoting filopodia delivery and shedding spheroid granules: Evidences from atomic force microscopy observation. J Dermatol Sci 76 : 222-230, 2014.

65. Bach EA, Aguet $M$ and Schreiber RD: The IFN gamma receptor: A paradigm for cytokine receptor signaling. Annu Rev Immunol 15: 563-591, 1997.

66. Carnaud C, Lee D, Donnars O, Park SH, Beavis A, Koezuka Y and Bendelac A: Cutting edge: Cross-talk between cells of the innate immune system: NKT cells rapidly activate NK cells. J Immunol 163: 4647-4650, 1999.

67. Frucht DM, Fukao T, Bogdan C, Schindler H, O'Shea JJ and Koyasu S: IFN-gamma production by antigen-presenting cells: Mechanisms emerge. Trends Immunol 22: 556-560, 2001.

68. Flaishon L, Hershkoviz R, Lantner F, Lider O, Alon R, Levo Y, Flavell RA and Shachar I: Autocrine secretion of interferon gamma negatively regulates homing of immature B cells. J Exp Med 192: 1381-1388, 2000.

69. Harris JE, Harris TH, Weninger W, Wherry EJ, Hunter CA and Turka LA: A mouse model of vitiligo with focused epidermal depigmentation requires IFN- $\gamma$ for autoreactive $\mathrm{CD}^{+} \mathrm{T}$-cell accumulation in the skin. J Invest Dermatol 132: 1869-1876, 2012

70. Gregg RK, Nichols L, Chen Y, Lu B and Engelhard VH: Mechanisms of spatial and temporal development of autoimmune vitiligo in tyrosinase-specific TCR transgenic mice J Immunol 184: 1909-1917, 2010.

71. Yang L, Wei Y, Sun Y, Shi W, Yang J, Zhu L and Li M: Interferon-gamma inhibits melanogenesis and induces apoptosis in melanocytes: A pivotal role of CD8+ cytotoxic T lymphocytes in vitiligo. Acta Derm Venereol 95: 664-670, 2015.

72. Natarajan VT, Ganju P, Singh A, Vijayan V, Kirty K, Yadav S, Puntambekar S, Bajaj S, Dani PP, Kar HK, et al: IFN- $\gamma$ signaling maintains skin pigmentation homeostasis through regulation of melanosome maturation. Proc Natl Acad Sci USA 111: 2301-2306, 2014

73. Kristensen M, Chu CQ, Eedy DJ, Feldmann M, Brennan FM and Breathnach SM: Localization of tumour necrosis factor-alpha (TNF-alpha) and its receptors in normal and psoriatic skin: Epidermal cells express the $55-\mathrm{kD}$ but not the $75-\mathrm{kD}$ TNF receptor. Clin Exp Immunol 94: 354-362, 1993.

74. Kholmanskikh O, van Baren N, Brasseur F, Ottaviani S, Vanacker J, Arts N, van der Bruggen P, Coulie P and De Plaen E: Interleukins 1alpha and 1beta secreted by some melanoma cell lines strongly reduce expression of MITF-M and melanocyte differentiation antigens. Int J Cancer 127: 1625-1636, 2010.

75. Martin MU and Wesche H: Summary and comparison of the signaling mechanisms of the Toll/interleukin-1 receptor family. Biochim Biophys Acta 1592: 265-280, 2002.

76. Tang A and Gilchrest B: Regulation of keratinocyte growth factor gene expression in human skin fibroblasts. J Dermatol Sci 11: 41-50, 1996

77. Grewe M, Gyufko K, Budnik A, Ruzicka T, Olaizola-Horn S, Berneburg $M$ and Krutmann J: Interleukin-1 receptors type I and type II are differentially regulated in human keratinocytes by ultraviolet B radiation. J Invest Dermatol 107: 865-870, 1996

78. Kondo S, Sauder DN, Kono T, Galley KA and McKenzie RC: Differential modulation of interleukin-1 alpha (IL-1 alpha) and interleukin-1 beta (IL-1 beta) in human epidermal keratinocytes by UVB. Exp Dermatol 3: 29-39, 1994.

79. Chen N, Hu Y, Li WH, Eisinger M, Seiberg M and Lin CB The role of keratinocyte growth factor in melanogenesis: A possible mechanism for the initiation of solar lentigines. Exp Dermatol 19: 865-872, 2010

80. Sims J, March C, Cosman D, Widmer MB, MacDonald HR, McMahan CJ, Grubin CE, Wignall JM, Jackson JL, Call SM, et al: cDNA expression cloning of the IL-1 receptor, a member of the immunoglobulin superfamily. Science 241: 585-589, 1988.

81. Barata LT, Ying S, Meng Q, Barkans J, Rajakulasingam K, Durham SR and Kay AB: IL-4- and IL-5-positive T lymphocytes, eosinophils, and mast cells in allergen-induced late-phase cutaneous reactions in atopic subjects. J Allergy Clin Immunol 101: 222-230, 1998.
82. Min B, Prout M, Hu-Li J, Zhu J, Jankovic D, Morgan ES, Urban JF Jr, Dvorak AM, Finkelman FD, LeGros G and Paul WE: Basophils produce IL-4 and accumulate in tissues after infection with a Th2-inducing parasite. J Exp Med 200: 507-517, 2004

83. Imran M, Laddha N, Dwivedi M, Mansuri MS, Singh J, Rani R, Gokhale RS, Sharma VK, Marfatia YS and Begum R: Interleukin-4 genetic variants correlate with its transcript and protein levels in patients with vitiligo. Br J Dermatol 167: 314-323, 2012

84. Salgame P, Abrams JS, Clayberger C, Goldstein H, Convit J, Modlin RL and Bloom BR: Differing lymphokine profiles of functional subsets of human CD4 and CD8 T cell clones. Science 254: 279-282, 1991.

85. Basak PY, Adiloglu AK, Ceyhan AM, Tas T and Akkaya VB: The role of helper and regulatory $\mathrm{T}$ cells in the pathogenesis of vitiligo. J Am Acad Dermatol 60: 256-260, 2009.

86. Nouri-Koupaee A, Mansouri P, Jahanbini H, Sanati MH and Jadali Z: Differential expression of mRNA for T-bet and GATA-3 transcription factors in peripheral blood mononuclear cells of patients with vitiligo. Clin Exp Dermatol 40: 735-740, 2015

87. Hirano T, Ishihara K and Hibi M: Roles of STAT3 in mediating the cell growth, differentiation and survival signals relayed through the IL-6 family of cytokine receptors. Oncogene 19: 2548-2556, 2000.

88. Speeckaert R, Lambert J, Grine L, Van Gele M, De Schepper S and van Geel N: The many faces of interleukin-17 in inflammatory skin diseases. Br J Dermatol 175: 892-901, 2016.

89. Volpe E, Servant N, Zollinger R, Bogiatzi SI, Hupé P, Barillot E and Soumelis V: A critical function for transforming growth factor-beta, interleukin 23 and proinflammatory cytokines in driving and modulating human $\mathrm{T}(\mathrm{H})-17$ responses. Nat Immunol 9: 650-657, 2008.

90. Kang WH, Yoon KH, Lee ES, Kim J, Lee KB, Yim H, Sohn S and Im S: Melasma: Histopathological characteristics in 56 Korean patients. Br J Dermatol 146: 228-237, 2002.

91. Nakajima M, Shinoda I, Fukuwatari Y and Hayasawa H: Arbutin increases the pigmentation of cultured human melanocytes through mechanisms other than the induction of tyrosinase activity. Pigment Cell Res 11: 12-17, 1998.

92. Palumbo A, d'Ischia M, Misuraca G and Prota G: Mechanism of inhibition of melanogenesis by hydroquinone. Biochim Biophys Acta 1073: 85-90, 1991

93. Smith CJ, O'Hare KB and Allen JC: Selective cytotoxicity of hydroquinone for melanocyte-derived cells is mediated by tyrosinase activity but independent of melanin content. Pigment Cell Res 1: 386-389, 1988.

94. Wang X and Zhang Y: Resveratrol alleviates LPS-induced injury in human keratinocyte cell line $\mathrm{HaCaT}$ by up-regulation of miR-17. Biochem Biophys Res Commun 501: 106-112, 2018.

95. Kim ES, Chang H, Choi H, Shin JH, Park SJ, Jo YK, Choi ES, Baek SY, Kim BG, Chang JW, et al: Autophagy induced by resveratrol suppresses a-MSH-induced melanogenesis. Exp Dermatol 23: 204-206, 2014

96. Salzes C, Abadie S, Seneschal J, Whitton M, Meurant JM, Jouary T, Ballanger F, Boralevi F, Taieb A, Taieb $\mathrm{C}$ and Ezzedine K: The vitiligo impact patient scale (VIPs): Development and validation of a vitiligo burden assessment tool. J Invest Dermatol 136: 52-58, 2016.

97. Moretti S, Spallanzani A, Amato L, Hautmann G, Gallerani I, Fabiani $\mathrm{M}$ and Fabbri P: New insights into the pathogenesis of vitiligo: Imbalance of epidermal cytokines at sites of lesions. Pigment Cell Res 15: 87-92, 2002.

98. Moretti S, Fabbri P, Baroni G, Berti S, Bani D, Berti E, Nassini R, Lotti T and Massi D: Keratinocyte dysfunction in vitiligo epidermis: Cytokine microenvironment and correlation to keratinocyte apoptosis. Histol Histopathol 24: 849-857, 2009.

99. Kim NH, Jeon S, Lee HJ and Lee AY: Impaired PI3K/Akt activation-mediated NF-kappaB inactivation under elevated TNF-alpha is more vulnerable to apoptosis in vitiliginous keratinocytes. J Invest Dermatol 127: 2612-2617, 2007

100. Barygina V, Becatti M, Lotti T, Moretti S, Taddei N and Fiorillo C: Treatment with low-dose cytokines reduces oxidative-mediated injury in perilesional keratinocytes from vitiligo skin. J Dermatol Sci 79: 163-170, 2015.

101. Debbaneh MG, Levin E, Sanchez Rodriguez R, Leon A, Koo J and Rosenblum MD: Plaque-based sub-blistering dosimetry: Reaching PASI-75 after two treatments with 308-nm excimer laser in a generalized psoriasis patient. J Dermatolog Treat 26: $45-48,2015$ 
102. Grimes P, Morris R, Avaniss-Aghajani E, Soriano T, Meraz M and Metzger A: Topical tacrolimus therapy for vitiligo: Therapeutic responses and skin messenger RNA expression of proinflammatory cytokines. J Am Acad Dermatol 51: 52-61, 2004.

103. Sakuma S, Higashi Y, Sato N, Sasakawa T, Sengoku T, Ohkubo Y, Amaya T and Goto T: Tacrolimus suppressed the production of cytokines involved in atopic dermatitis by direct stimulation of human PBMC system. (Comparison with steroids). Int Immunopharmacol 1: 1219-1226, 2001.

104. Birol A, Kisa U, Kurtipek GS, Kara F, Kocak M, Erkek E and Caglayan O: Increased tumor necrosis factor alpha (TNF-alpha) and interleukin 1 alpha (IL1-alpha) levels in the lesional skin of patients with nonsegmental vitiligo. Int J Dermatol 45: 992-993, 2006.
105. Alghamdi K and Khurrum H: Methotrexate for the treatment of generalized vitiligo. Saudi Pharm J 21: 423-424, 2013.

106. Grimes PE, Hamzavi I, Lebwohl M, Ortonne JP and Lim HW: The efficacy of afamelanotide and narrowband UV-B phototherapy for repigmentation of vitiligo. JAMA Dermatol 149: 68-73, 2013.

(i) (-) This work is licensed under a Creative Commons Attribution-NonCommercial-NoDerivatives 4.0 International (CC BY-NC-ND 4.0) License. 